\title{
NÚCLEO DE ESTUDOS DE ECONOMIA AGRÍCOLA (NE²AGRO IPEA-MAPA) ${ }^{1}$
}

José Eustáquio Ribeiro Vieira Filho²

\section{INTRODUÇÃO}

O Núcleo de Estudos de Economia Agrícola (NE²AGRO) é um grupo de pesquisa vinculado ao Ipea, mas com o apoio financeiro e o direcionamento das demandas técnicas definidas pelo Mapa. Esse arranjo institucional busca apoiar e subsidiar a tomada de decisão ministerial na formulação e na avaliação de políticas públicas relacionadas ao desenvolvimento do setor agropecuário.

Por meio do termo de execução descentralizada (TED), assinado entre o Ipea e o Mapa em dezembro de 2019, o NE²AGRO foi criado no início de 2020, com a contratação de vários pesquisadores e economistas. $\mathrm{O}$ grupo de pesquisa está diretamente vinculado à Dirur/Ipea e à Secretaria Executiva do Mapa.

\section{FIGURA 1}

Logotipo institucional do $\mathrm{NE}^{2} \mathrm{AGRO}$

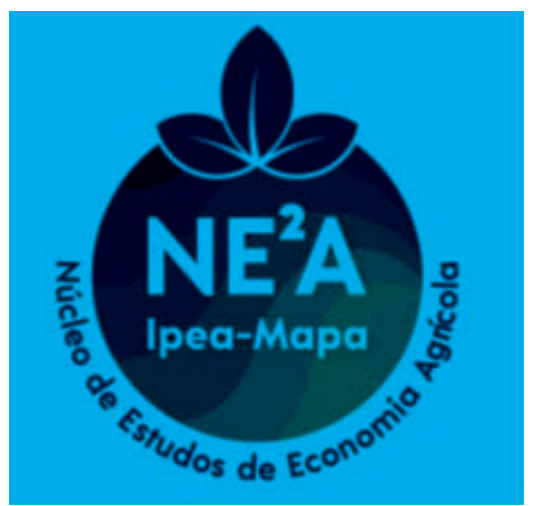

Fonte: Mapa.

1. DOI: http://dx.doi.org/10.38116/brua24art10

2. Técnico de planejamento e pesquisa na Diretoria de Estudos e Políticas Regionais, Urbanas e Ambientais (Dirur) do Ipea; diretor de programa da Secretaria Executiva do Ministério da Agricultura, Pecuária e Abastecimento (Mapa); e professor do Programa de Pós-Graduação em Agronegócio da Universidade de Brasília (Propaga/UnB) e em Economia da Universidade Federal de Viçosa (UFV).E-mail: <jose.vieira@ipea.gov.br>. 
Deve-se ressaltar que o $\mathrm{NE}^{2} \mathrm{AGRO}$ Ipea-Mapa é uma ideia inovadora, que visa construir uma rede de pesquisa baseada em três pilares.

1) Elaboração e execução de políticas produtivas, conduzidas e coordenadas pelo Mapa.

2) Avaliação de impacto de políticas públicas, desenvolvida e monitorada pelo Ipea.

3) Interação com a sociedade científica e com órgãos de pesquisa, tais como as universidades de excelência na área de economia agrícola, as instituiçóes estaduais de pesquisa, bem como o Instituto Brasileiro de Geografia e Estatística (IBGE), entre outros.

\section{OBJETIVO E COOPERAÇÃO DE PESQUISA}

O plano de trabalho estabelece as metas a serem atingidas na criação do grupo de pesquisa, visando realizar açôes de cooperaçáo técnico-científica, intercâmbio de conhecimentos, informaçóes e experiências entre as duas instituiçôes, que assegurem a realização de estudos para o fomento e o desenvolvimento de políticas públicas do setor agropecuário brasileiro.

O Ipea realizou, em dois volumes, um amplo diagnóstico da economia brasileira em 2018. O primeiro volume tratou do crescimento econômico e das várias agendas associadas, tais como o regime fiscal, o mercado de trabalho, a previdência, a reforma tributária, a educação, a saúde, a pesquisa, a matriz energética, a inserção internacional e outros temas (Ipea, 2018a). O segundo volume procurou avaliar a sustentabilidade do crescimento em três dimensôes: i) cooperaçáo federativa e soberania nacional; ii) infraestrutura para o desenvolvimento; e iii) sustentabilidade e competitividade setorial. No segundo volume e na terceira dimensão, foi escrito um breve diagnóstico setorial do agronegócio brasileiro (Ipea, 2018b).

Observou-se que o setor agropecuário foi bastante estudado nos últimos anos. ${ }^{3} \mathrm{O}$ Ipea foi importante na avaliação de políticas, que visou ao desenvolvimento setorial e apresentou os riscos de continuidade da produçấo diante da demanda crescente por alimentos. Em 2018, o IBGE divulgou os resultados preliminares do censo agropecuário de 2017. Uma avaliação mais criteriosa dos dados pode ilustrar, sem dúvida, mudanças relacionadas à estrutura produtiva do setor agropecuário. É fato que um estudo mais aprofundado dos dados sinalizará uma gama enorme de questôes a serem estudadas sobre o setor agropecuário brasileiro. $\mathrm{O}$ acesso aos dados por indivíduos e a elaboração de pesquisas técnicas permitirão uma profunda análise produtiva.

Conforme Ipea (2018b), o instituto havia elaborado soluçôes propositivas ao setor agropecuário, no intuito de reduzir as dificuldades econômicas e estruturais do crescimento econômico. Uma das propostas, relacionada ao agronegócio, era a de se criar, no âmbito do Mapa, da Empresa Brasileira de Pesquisa Agropecuária (Embrapa) ou do próprio Ipea, uma instituiçáo de estudos econômicos do agronegócio que pudesse auxiliar no planejamento estratégico do setor e na elaboração e avaliação de políticas públicas de desenvolvimento pelo governo. A criação do $\mathrm{NE}^{2} \mathrm{AGRO}$ está inserida nessa proposta, que se germinou nos trabalhos institucionais do Ipea.

3. Para trabalhos desenvolvidos no âmbito do Ipea e de instituições parceiras, conferir Gasques, Vieira Filho e Navarro (2010), Gasques et al. (2012), Campos e Navarro (2013), Buainain et al. (2014), Vieira Filho e Gasques (2016), Buainain, Lanna e Navarro (2019), Vieira Filho (2019) e Fishlow e Vieira Filho (2020). 


\section{LINHAS DE PESQUISA}

As linhas temáticas de estudo estão baseadas em sete grandes eixos: i) agricultura familiar e cooperativismo; ii) câmaras setoriais e temáticas; iii) irrigação e diversificação da riqueza; iv) sistema nacional de inovação; v) censo agropecuário (novo diagnóstico); vi) observatório do setor agropecuário; e vii) economia internacional (com a inclusão da temática da economia chinesa nesse contexto). Deve-se ressaltar, contudo, que existem esforços para ampliar as áreas de pesquisa, a fim de que possam incluir novas áreas de interesse, como a questão ambiental e produtiva, bem como a de segurança fundiária e jurídica do sistema produtivo brasileiro.

De forma resumida, as áreas temáticas já criadas se encontram nas subseçôes a seguir.

\subsection{Eixo 1: agricultura familiar e cooperativismo}

As práticas cooperativistas e o fomento do associativismo possibilitam melhores condiçóes de negociação aos pequenos agricultores, aumentando a sua renda e a capacidade de absorção de novas tecnologias. Essa linha buscará a discussão do impacto das falhas de mercado nesse contexto.

\subsection{Eixo 2: câmaras setoriais e temáticas}

Compreende análises sobre instruçôes normativas, processos produtivos, aplicação de defensivos, comercialização e aparato tributário em relação ao adensamento, à sustentabilidade e à competitividade das cadeias de valores, considerando propostas para políticas voltadas para a parceria público-privada.

\subsection{Eixo 3: irrigação e diversificação da riqueza}

A política de irrigação induz a modernização agrícola e a industrialização, com reflexos diretos e indiretos sobre a redução da pobreza no campo e sobre a retenção do êxodo rural. Essa linha buscará explorar as externalidades positivas da irrigação no desenvolvimento socioeconômico.

\subsection{Eixo 4: sistema nacional de inovação}

Buscará propor práticas de gestão inovadoras que forneçam maior flexibilidade e dinamismo gerencial às redes de inovação, explorando o conceito de agilidade, no caso da Embrapa, em seus processos de pesquisa, desenvolvimento e inovaçáo.

\subsection{Eixo 5: censo agropecuário - novo diagnóstico}

Avaliará as diversas políticas entre as últimas contagens censitárias, de modo a propor a manutenção ou a reavaliação dos instrumentos de intervençáo para a melhoria de açôes relacionadas às transformaçôes das atividades agropecuárias, florestais e aquícolas, e também no meio rural.

\subsection{Eixo 6: observatório do setor agropecuário}

Buscará facilitar o acesso a informações mais qualificáveis e georreferenciadas em relação a produção pecuária, irrigação, agricultura familiar e desenvolvimento econômico e ambiental, contribuindo para a prevenção de riscos e aumentando o dinamismo dos processos decisórios do Mapa.

\subsection{Eixo 7: economia internacional}

Essa linha de pesquisa busca subsidiar as decisóes ministeriais nas tratativas negociadoras e em foros internacionais, além de estudar as implicaçóes de movimentos comerciais para 
a competitividade do setor produtivo nacional. Ademais, análises específicas em relação à China serão focadas. Pretende-se auxiliar na formulação de objetivos de médio e longo prazo para a relaçáo do Brasil com a China no setor.

\section{PARCERIA INSTITUCIONAL}

Um bom planejamento de pesquisa é necessário, a ponto de subsidiar as decisões estratégicas do Mapa. É nesse sentido que se definiu a parceria Ipea-Mapa. Essa parceria institucional é uma forma de o Mapa estimular outros órgáos do governo a estudar o setor agropecuário. Uma correta avaliação econômica será importante para subsidiar as decisóes ministeriais. O Mapa fará as transferências dos recursos ao Ipea, que terá como função utilizar sua expertise em pesquisa econômica para montar o grupo de pesquisa, dando todo o apoio institucional ao desenvolvimento das pesquisas.

Existem diversas modalidades de bolsas implementadas, presenciais no Ipea e não presenciais. É importante, na constituição do grupo, manter bolsas não presenciais em instituiçóes acadêmicas e de pesquisas relevantes, como IBGE, UFV, bem como a Escola Superior de Agricultura Luiz de Queiroz da Universidade de São Paulo (Esalq/USP). Busca-se, assim, envolver mais atores dentro do grupo de forma a diversificar os pontos de vista e as análises, no intuito de ampliar a rede de pesquisa.

Objetivamente, caberá ao Mapa:

- efetuar a transferência dos créditos orçamentários e recursos financeiros ao Ipea;

- acompanhar as atividades de execução, avaliando os seus resultados; e

- analisar o relatório de cumprimento do objeto das pesquisas.

Ao Ipea, destinam-se as tarefas a seguir:

- promover a execução e o acompanhamento do objeto das pesquisas na forma e no prazo estabelecidos;

- aplicar os recursos discriminados exclusivamente na consecução do acordo de cooperação;

- permitir e facilitar o acesso a toda a documentação e às informaçóes do projeto ao Mapa; e

- apresentar o relatório final aos interessados dentro do Mapa.

Conjuntamente, as duas instituiçóes devem:

- orientar, supervisionar e cooperar para a implantação das açóes que sáo objeto de cooperação; e

- definir temas de pesquisas a serem estudados que tenham a finalidade de subsidiar a avaliaçáo de políticas públicas relacionadas ao desenvolvimento do setor de economia agrícola.

Como produtos, espera-se a publicação de livros, artigos, textos para discussão, bem como a elaboração de dois relatórios finais, que sejam validados pela Dirur/Ipea e pelo Mapa.

\section{RESULTADOS ESPERADOS}

Além da aproximação do desenvolvimento da pesquisa aplicada, entende-se que essa parceria inovadora aprofundará temas de interesse relacionados ao desenvolvimento do setor agropecuário brasileiro; realizará a avaliação de políticas públicas de fomento produtivo; sistematizará a base de dados de modo a extrair informaçôes relevantes, que possam contribuir 
para a formulação de políticas públicas; e traçará um novo diagnóstico do setor agropecuário brasileiro, conforme os dados do novo censo agropecuário.

\section{EQUIPE DE TRABALHO}

A equipe está constituída em coordenadores técnicos, pesquisadores associados e assistentes de pesquisa e estatística.

- Coordenadores técnicos: José Eustáquio Ribeiro Vieira Filho (Mapa) e Júnia Cristina Peres R. da Conceição (Ipea).

- Pesquisadores associados: Eliseu Roberto de Andrade Alves (Embrapa), José Garcia Gasques (Mapa), Edward Martins Costa (Universidade Federal do Ceará - UFC), José Gustavo Feres (Ipea), Marcelo Dias Paes Ferreira (Universidade Federal de Goiás - UFG), Marcelo José Braga (UFV), Marcus Peixoto (Senado Federal) e Marlon Vinícius Brisola (UnB).

- Assistentes de pesquisa e estatística - Rio de Janeiro: Carlos Andres Charris Vizcaino (UFV e Ipea) e Rayssa Alexandre Costa (Ipea).

- Assistentes de pesquisa - Brasília: Daniela Vasconcelos de Oliveira (Ipea), Érica Basílio Tavares Ramos (UFG e Ipea), Felipe Pinto da Silva (Ipea e Universidade Estadual de Campinas - Unicamp), Maicon Gonçalves Monteiro (Propaga/UnB e Ipea) e Zenaide Rodrigues Ferreira (UnB e Ipea).

- Assistente de pesquisa - São Carlos: Sílvia Ronsom (USP e Ipea).

Mais informaçóes estáo disponíveis na Diretoria de Programa da Secretaria Executiva do Mapa (Esplanada dos Ministérios, bloco D, nono andar, sala 918 - Brasília/Distrito Federal - CEP 70.043-900), no telefone +55 (61) 3218-2598, no e-mail <jose.eustaquio@ agricultura.gov.br> e no site <www.agricultura.gov.br>.

\section{REFERÊNCIAS}

BUAINAIN, A. M. et al. O mundo rural no Brasil do século 21: a formação de um novo padrão agrário e agrícola. Brasília: Embrapa; Editora Unicamp, 2014.

BUAINAIN, A. M.; LANNA, R.; NAVARRO, Z. Agricultural development in Brazil: the rise of a global agro-food power. New York: Routledge, 2019.

CAMPOS, S. K.; NAVARRO, Z. (Org.). A pequena produçáo rural e as tendências do desenvolvimento agrário brasileiro: ganhar tempo é possível? Brasília: CGEE, 2013.

FISHLOW, A; VIEIRA FILHO, J. E. R. Agriculture and industry in Brazil: innovation and competitiveness. New York: Columbia University Press, 2020.

GASQUES, J. G. et al. Total factor productivity in Brazilian agriculture. In: FUGLIE, K. O.; WANG, S. L.; BALL, V. E. (Eds.). Productivity growth in agriculture: an international perspective. Oxfordshire: CAB International, 2012.

GASQUES, J. G.; VIEIRA FILHO, J. E. R.; NAVARRO, Z. (Org.). A agricultura brasileira: desempenho, desafios e perspectivas. Brasília: Ipea, 2010.

IPEA - INSTITUTO DE PESQUISA ECONÔMICA APLICADA. Desafios da naçáo. Brasília: Ipea; MDGP, 2018a. v. 1.

Desafios da naçáo. Brasília: Ipea; MDGP, 2018b. v. 2. 
VIEIRA FILHO, J. E. R. (Org.). Diagnóstico e desafios da agricultura brasileira. Brasília: Ipea, 2019.

VIEIRA FILHO, J. E. R.; GASQUES, J. G. (Org.). Agricultura, transformação produtiva e sustentabilidade. Brasília: Ipea, 2016. 